\title{
Reducing Language Barriers in Science for Students with Special Educational Needs
}

\author{
Susannah Boyle \\ Department of Early, Middle, and Exceptional Education, \\ Millersville University, Millersville, PA 17551, USA \\ susannah.boyle@millersville.edu
}

\author{
Karen L. Rizzo \\ College of Education and Counseling, Saint Martin's University, \\ Lacey, WA 98503, USA \\ krizzo@stmartin.edu
}

Jonte C. Taylor

Corresponding author,

Department of Educational Psychology, Counseling, and Special Education, Pennsylvania State University, University Park, PA 16802, USA

jct215@psu.edu

Received: 15July 2020 | Revised: 1 November 2020 |

Accepted: 6 November 2020

\begin{abstract}
An increased focus on science instruction and science learning for students with special education needs has been growing over the past decade. Research studies, particularly meta-analyses focused on science for students with disabilities, show investigators are interested in what science strategies and approaches (e.g., graphic organizers, inquiry-based instruction,) work for students regardless of identified need (e.g., learning disabilities). However, researchers have noted that science instruction can often rely heavily on text and have burdensome reading demands that may cause students with disabilities to struggle. Research suggests that incorporating Universal Design for Learning (UDL), multimodal representation, the arts, and communicative technologies can reduce the language load for learning science content and


phenomena for students with special education needs. The purpose of this paper is to provide resources and suggestions for reducing the language barriers in science for students with special education needs through the use of multimodal representation and communication technologies.

\section{Keywords}

science - students with disabilities - multimodal representation - assistive technology - augmentative and alternative communication

\section{$1 \quad$ Introduction}

Science phenomena are a part of every aspect of life and human existence. Every element of life is dependent upon scientific interactions, including chemistry, biology, physical science, and Earth science. In essence, all aspects of science are connected to each other and connected to us as human beings. However, the province of science learning can often be restricted to only those individuals with resources, means, and "ability." The disposition to only encourage science learning to those who deserve or have earned it is shortsighted and discriminatory. The exclusion of any group of students' opportunities to participate in science is not new or relegated to any specific region of the world. While some countries are considered more progressive in broadening the scope of science participation across various underrepresented populations, there is still a long way to go. For example, while the United States has made considerable progress in including students with special educational needs (SEN) in science instruction, research reviews show a considerable dearth of research on effective instructional or strategic approaches on science learning (Dexter et al., 2011; Rizzo \& Taylor, 2016; Taylor et al., 202O; Therrien et al., 2011; Therrien et al., 2014). In addition, there has been considerable global movement to include SEN students in science, particularly through the "science for all" movement.

\subsection{Global Science Initiatives for SEN Students}

Globally, there has been a shift in where and how SEN students are taught. General education classrooms, as opposed to specialized schools or classrooms, are the preferred locations for instruction for SEN students around the world (Lartec \& Espique, 2012; Sharma et al., 2008). Through the years, particularly beginning in the $198 \mathrm{O}$, inclusion of SEN students in science has become a 
broader worldwide initiative. The United Kingdom's Swann Report, Education for All, set the stage for including marginalized students in general education classrooms, including science classrooms (Villanueva et al., 2012). The Project 2061 initiative from the American Association for the Advancement of Science (AAAS, 1990) and United Nations Educational, Scientific, and Cultural Organization's Salamanca Statement (UNEsco, 1994) have placed greater emphasis on science for global citizenry, including SEN students. While SEN students were not the main focus of either of these initiatives, they both mention SEN students in their statements as part of inclusive science education. The Salamanca Statement asserted the educational rights of all students, which includes those with physical, intellectual, social, emotional, linguistic, or other conditions. Project 2061's declared goals were advancement of human scientific progress and providing diversified communities, including women, minorities, and the disabled, opportunities in science.

As highlighted by Villanueva and Hand (2011) and Miller (2004), science education has proceeded to promote holistic ideas in the service of science for all, including a focus on the nature of science and technology and society. Introduced by Fensham (1985), the notion of "science for all" focused on science and accessibility of science opportunities to a wider scope of students. By broadening science to include more individuals, such as SEN students, success in science can be achieved. Particularly as it relates to SEN students, UNESCO asserted the global educational rights of students with physical, intellectual, social, emotional, and linguistic struggles to have opportunities to learn and practice science and gain science literacy (UNESCO, 1994). Unfortunately, despite the measures taken, making science meaningful for all has so far not been successful regardless of how that success is evaluated (Villanueva et al., 2012). This is due to numerous factors for SEN students, including little to no motivation to learn science, lack of employment prospects, and limited practical understanding of science (Fensham, 2008; Jegede \& Kyle, 2007; Roberts, 2007). Two main reasons for these outcomes for SEN students involve (a) a lack of true motivation and understanding of the importance of the science for all initiative by practitioners and (b) lack of skill to make science for all truly possible.

\subsection{Theoretical Framework and Discussion Questions}

The barriers that hinder science learning success for SEN students have been addressed by increasing amounts of research and intervention studies across student needs such as learning disabilities (LD; Mastropieri et al., 2006), emotional and behavioral disorders (EBD; Bowman-Perrott et al., 2007), autism spectrum disorder (ASD; Knight et al., 2012), visual impairments (VI; Farrand 
et al., 2016), intellectual and developmental disabilities (IDD; Heinrich et al., 2016), and hearing impairments (HI; Kurz et al., 2015). While the past decade has seen an increase in attention to science teaching and learning for SEN students, most of those studies have had a language component that was considered part of the study. Overcoming language barriers, although not always the focus of each study, was essential in completing this research.

For example, Bowman et al. (2007) focused on the effect of class-wide peer tutoring (CWPT) as an intervention for students with EBD during an inquirybased science lesson. The focus of this study was not language; however, CWPT requires effective communication between peers and between students and the teacher. Thus, language is important. As another example, Kurz et al. (2015) examined how science content learning differed for students with HI when using direct instruction and interpreted instruction. These studies represent two examples of the types of the language barriers that may exist for SEN students when teaching and learning science.

Science language barriers for SEN students can fall into three broad categories that include sensory barriers, expressive/receptive language barriers, and content language barriers. Sensory barriers are challenges that can primarily be attributed to difficulty connected to the use of one or more of the five physiological senses, particularly vision and hearing. Interventions and accommodations for these students should mainly address sensory barriers related to increasing science language access to students who are deaf or hard of hearing and students who are blind or have reduced vision acuity. Lartec and Espique (2012) highlighted the need for science teachers to focus on language learning acquisition as part of content communication for students with VI. For students with HI, research suggests that science content knowledge should be built simultaneously with language development (Kurz et al., 2015; Sunal \& Burch, 1982). Science language barriers that are a result of expressive or receptive language difficulties primarily effect students with LD (Therrien et al., 2011), EBD (Therrien et al., 2014), and ASD (Taylor et al., 2020). Receptive (processing and comprehension) and expressive (articulation and indicative) language difficulties can be evident in both oral and written communications. Gardner (1974) identified multiple considerations with difficulties related to science language including a) cognitive processes for technical science vocabulary, b) contextual science discourse with specialized science language, and c) science language structure (word/sentence length and passive voice). In addressing science language barriers for SEN students, examination of language, science, and science language challenges need to be considered.

Science educators want all students to learn and appreciate science concepts. However, there is a significant disconnect when teaching science to SEN 
students (Kahn \& Lewis, 2014). This may be particularly evident in teaching science to SEN students who are less likely to be in inclusive classrooms (e.g., students with moderate or severe cognitive or developmental exceptionalities). If teachers do not understand the benefit of teaching all students, including those SEN students that are more moderate to severe, the entire notion of science for all is lost.

A major barrier to science learning for all SEN students is the connection of science, language, and literacy. Language and literacy command a large focus in science learning, which may hinder the opportunities for SEN students to participate in and ultimately learn science content and concepts. The need for science educators (and special educators as well) is paramount if we are to increase science-related outcomes for students with special needs. Three ways that teachers can support SEN students in science classrooms and reduce language demands are using a) the Universal Design for Learning (UDL) framework, b) multimodal representations (MMR), and c) communicative systems. The purpose of this paper is to provide support for educators in providing science instruction to all students, especially SEN students, regardless of severity of exceptionality. The following questions drive the discussions within this paper:

1. What are the science language barriers to science achievement for SEN students?

2. What strategies and practices reduce the language and literacy barriers in science for SEN students?

The idea of science literacy for all was based on the notion that science requires language and language requires literacy for understanding. Language is an integral part of science, particularly for the purposes of sharing ideas, thoughts, challenges, and discoveries. Unfortunately, the heavy burden of language in science is often a barrier for SEN students (Therrien et al., 2011; Therrien et al., 2014). In fact, that barrier can be so significant that SEN students can often be left behind in science classrooms without the proper support. The barriers that SEN students experience can be encapsulated into three areas: language, science, and science language.

\subsection{Expressive/Receptive Language Barriers}

Acquiring and becoming fluent in science knowledge and inquiry skills typically requires comprehending and expressing concepts and vocabulary across 
a wide range of topics. Both receptive - the ability to understand what is being spoken to you - and expressive - the ability to communicate what you want to share - language skills are critically important. SEN students may face barriers in science because of a lack of either or both of these skills. Although information about global prevalence of speech and language impairments is hard to find, research from the United States and Australia suggests that rates could be quite high, with $7.7 \%$ and $13 \%$, respectively, reported (National Institute on Deafness and Other Communication Disorders, 2016; Macleod \& McKinnon, 2007). Such impairments include language disorders that can negatively affect receptive and expressive language skills. Students with H also commonly have difficulties with both receptive and expressive language skills (Lieu et al., 2010). Students can also have articulation, fluency, and voice disorders that affect their ability to be intelligible to teachers and classmates.

SEN students also include those with LD, who may have difficulties in oral language, reading, or both (Eisenmajer et al., 2005). It is important to note that a student with a reading disability may also struggle with understanding and expressing oral language. Such students may need accommodations and other support in not only reading scientific texts, but in understanding lectures, taking part in class discussions, and participating in experiments and other projects with a partner or small group. Meaningful inclusion for SEN students in science involves designing supports for speaking and listening as well as reading and writing.

Students with ASD and other significant disabilities should also be considered when focusing on science for all. ASD is a social communication disorder, and many individuals with ASD find it difficult to interact with others (American Psychiatric Association, 2013), especially in unpredictable situations. Unless carefully scaffolded, this could hinder meaningful participation in inquiry learning and other interactive activities in the science curriculum. Furthermore, roughly half of individuals with ASD have complex communication needs (CCN) (Lord \& Bishop, 2010), meaning that they have no or inadequate oral speech to communicate their feelings, needs, or thoughts. This clearly presents a significant barrier to participating in class discussion and group activities. Students with other disabilities, such as cerebral palsy, intellectual disabilities, or traumatic brain injury, may also present with CCN and may need individualized supports to be successful in the science classroom.

\subsection{Sensory Barriers}

Classroom instruction for students with sensory challenges (e.g., VI and HI) is often focused on language and content separately, to the detriment of science learning (Kurz et al., 2015; Lane-Outlaw, 2009; Lartec \& Espique, 2012). It is 
crucial to remember that SEN students that experience sensory barriers may not have cognitive or learning disabilities (Lartec \& Espique, 2012). Due to the nature of sensory impairments, it is necessary to consider additional avenues to learning and adjusting for language concerns. For SEN students that have sensory barriers, language inputs need to be different than traditional means that involve other senses and inputs (Sahin \& Yorek, 2009). Science teachers will need to adjust their instruction, especially considering students with low vision, blindness, hearing loss, or deafness. The importance of overcoming sensory barriers in language is particularly important as highlighted by Lartec and Espique (2012), in that language is the foundation of communication. The need to find accommodations, strategies, and frameworks that focus on decreasing sensory barriers and language challenges in science is essential.

\subsection{Science Content Language Barriers}

The barriers in science learning for SEN students can be attributed to three streams of reasoning: a) challenges related to their exceptionality, b) lack of attention in science education or related research, and c) lack of training to teach science to students with special needs. For example, science learning often relies heavily on the ability to read, write, and perform mathematical computations, all of which can prove to be a challenge for students with specific exceptionalities (e.g., LD, ASD, and IDD). For some SEN students, the challenges may be related to elements that affect academic outcomes such as attention, focus, engagement, and classroom behavior (e.g., attention deficit/ hyperactivity disorder [ADHD] and EBD). Furthermore, in a review of inquirybased science instruction for students with special needs, Rizzo and Taylor (2016) found that SEN students were most successful in classrooms that provided support along with the inquiry-based teaching. Fortunately, bands of parents, teachers, and researchers have started focusing on the needs of SEN students individually and through organized groups. Evaluating the needs of SEN students in science has been a part of the science education conversation for a number of years. However, this focus has been limited in scope, as a small percentage of concerned bodies have been the ones to be deeply involved. Organizations such as Science Education for Students with Disabilities (SESD, http://www.sesdinfo.org), which is a part of the National Science Teaching Association (NSTA), have been working at the intersection of science and SEN students since the early 197os. From there, other organizations have developed committees and groups focused on the needs of SEN students (e.g., NSTA and the National Association of Research in Science Teaching [NARST]). While there is evidence of research and practical writings and publications focused on SEN students, the breadth of these manuscripts is limited and scant. For 
example, Therrien et al. (2011) and Therrien et al. (2014) examined quantitative research publications related to science learning for students with $\mathrm{LD}$ and EBD over 30 years. During that time only 12 on LD and 11 studies on EBD had been published since the 1980s. More recently, Taylor et al. (2020a) and Taylor et al. (2020b) reviewed publications on science and science-related learning for students with ASD and IDD from 2000 to 2018 and found 12 and 18 publications, respectively.

The limited number of publications over the span of decades alludes to the last barrier to science learning for SEN students: teacher preparation. Arguably, the most important factor in student learning is the skill of the instructor or teacher. Well-prepared teachers know how to provide access to science instruction to all students and can make accommodation as necessary. They are well versed in teaching methodology and, beyond that, have knowledge of strategies and frameworks that can support students with special needs. Unsurprisingly, teachers are not prepared properly to teach science to SEN students. Kahn and Lewis (2014) surveyed 1,088 K-12 science teachers and found that a vast majority felt unprepared to teach SEN students and felt that most of their training would be considered "on the job." Lack of training can lead to lack of confidence and skill, which contributes to any barrier that SEN students may have when it comes to science learning. Barriers with language and in science inevitably lead to challenges with content-specific science language.

Often the science-language barrier is related to the complexity in translating science information from English to other languages as well as the technical jargon associated with each of the sciences (Oyoo, 2015). The challenge and frustration associated with science literacy is not only common for English language learners (ELLS) but also individuals for whom English is their first language (Ling \& Soong, 2006). Common language barriers include a lack of prior knowledge, multiple-meaning words, jargon, and nominalization (Kaldenberg et al., 2014). These language factors have an impact on the development of science literacy for all learners. For SEN students, these factors can be further compounded by comprehension skill deficits relating to the structure, vocabulary, and the difficulty level of expository text (Gajria et al., 2007; Kaldenber et al., 2014) that are frequently used in science classrooms. Specific language and literacy barriers may include skills such as fluency, decoding, word recognition, prior knowledge/connections, poor meta-cognitive skills, visualizing and verbalizing, and organizing new information (Kaldenberg et al., 2014). When students are not fluent in reading, the process of reading to learn is time consuming with minimal advancement in comprehension. In addition, science becomes disinteresting when students have limited or no prior knowledge or relatable experiences. 
The challenge and lack of motivation for learning science deepens for SEN students who in addition to these issues often lack the skills to monitor, evaluate, assess, and set goals for their own learning. Furthermore, development of these skills in a language arts classroom setting does not automatically generalize to understanding expository text in the science classroom. Contextual factors including student interactions with textual resources, hands-on activities, and dialogue within the classroom community do not directly integrate with application of comprehension skills as applied in language arts settings. The generalization and expansion of comprehension skills in the science classroom will not occur naturally. Students who generally experience success in science may have the assets needed for continued access to upper level science courses. Other students will struggle. Students with special needs can experience exclusion. As teachers, we can prevent exclusion and frustration by adopting a language-learning perspective when teaching science (Lemke, 199o). Addressing language and literacy barriers to science includes building comprehension skills of expository resources within context. This is not merely teaching skills like main idea and inferencing, it includes arranging experiences that build background/prior knowledge, explicitly develop self-management skills, and provide time to improve metacognitive strategies. Addressing the language and literacy barriers to science opens access to science education. If the goal is to develop a society that supports and understands science that is both diverse and inclusive, then our teachers must include methods that address the language-of-science barrier that is all too common for most students and all too restrictive for SEN students.

\section{$3 \quad$ Reducing Science Language Barriers}

In an effort to reduce the heft of language for science learning and provide increased access to the science curriculum, instructional pedagogy must be considered. These considerations need to include additional pedagogical methods alongside traditional science teaching and learning. Pedagogically, the National Research Council (2012) identified components that contribute to K-12 inquiry-based science instruction. These components included teaching students to use hands-on activities and opportunities to engage with science phenomena, identify sources of and collect and interpret data, support science claims with evidence, practice constructive argumentation and cooperative learning, and practice science writing including the use of multimodal representations (MMRs). Increased use of MMRs in science teaching and learning is one way to reduce the emphasis of traditional textual language for SEN 
students. In addition to shifting the science pedagogical focus to emphasize MMRs, incorporating other pedagogical frameworks and can further support SEN students.

Another way to support students with special needs in science is to understand and use a Universal Design for Learning (UDL) framework in the science classrooms. CAST (2018) describes the UDL framework as a set of three principles for teaching and learning that emphasize using multiple ways and flexibility in representation, engagement, and action and expression. Israel et al. (2018) crystalized considerations that teachers employ when using a UDL framework that include addressing all students' barriers and challenges by proactively planning for instruction and assessment using multiple means. Furthermore, Israel et al. (2018) described the use of a UDL framework and its components in an inquiry-based science classroom as:

- providing multiple means of engagement through choice and options in questioning or classroom activities,

- providing multiple means of representation so students can receive information by using text, video, simulations, audio and other multimedia, and

- providing multiple means of action and expression that include using MMRs and performance- or production-based displays of understanding.

Incorporating the UDL framework aligns exceptionally well with existing science pedagogy. In reducing language barriers in science for SEN students, we propose the use of MMRs (including the arts) and the use of communication devices (i.e., assistive technology [AT] and alternative and augmentative communication $[\mathrm{AAC}])$. The following sections will detail the use of these strategies and tools to support students with special needs in science classrooms.

\subsection{Use of Multimodal Representations in Science for SEN Students}

MMRs, when teaching or during instructional opportunities, promote meaningful access in science courses. MMRs are considered a method of teaching in which the instructor and/or the student(s) use multiple modes (verbal, visual, performance, art, etc.) to express, develop, share, elaborate, and extend meaning (Waldrip et al., 2010). Using MMRs diminishes the language barrier that too often prevents SEN students from meaningful inclusion in the science classroom. Meaningful inclusion addresses access to the classroom environment, access to the teacher, and access to instructional opportunities within the learning community. The classroom environment broadly goes beyond the physical arrangement and resources to encompass the entirety of the classroom and school. This includes the academic, behavioral, and social actions and interactions of the learning community. In order for any student to be successful, the primary contribution to inclusion is the teacher 
(Darling-Hammond, 1998). Teacher access includes several variables including but not limited to the number of student-teacher interactions, teacher-student interactions, teacher observations of students, instructional methods utilized, and management system(s) in place. Accessing the classroom teacher may differ in appearance in different classrooms but should include interactions that involve active and accurate academic responding, regardless of age/grade level and educational structures, as this kind of interaction generally leads to better learning outcomes (Skinner et al., 2005). Using MMRs can support active academic responding and thus reduce the number of students excluded from science classrooms. When applied with purpose and intention, SEN students can experience meaningful engagement, understanding, action, and communication in the science classroom (Hand et al., 2016). MMRs can be organized within the UDL framework for providing means of engagement, representation, action, and expression that promote science for all.

The language and literacy barriers presented by expository resources can be leveled when MmRs are used by teachers and students. For example, a visual presentation of the water cycle as the teacher lectures promotes engagement, students "making rain" using a series of physical actions to make storm sounds reflects auditory and kinesthetic engagement. When students are actively engaged by the teacher, their interest, effort, persistence, and self-regulation skills can be developed within the UDL framework. SEN students have not historically engaged with science expository resources, but providing multiple modes of representation and explicitly using such representations to connect the language and literacy of science could increase the likelihood of engagement (Kaldenberg et al., 2014; Tang et al., 2014). When teachers use MMRs to improve student engagement, the perceptions, language, and comprehension of SEN students is supported in the science classroom.

Choice also increases engagement (Erwin, 2004). When students are provided with multiple options to create meaning of science concepts, they are using MMRs as a tool for learning. MMRs (displays, role-play, songs, writings, models, the arts, experiments, etc.) provide different avenues of exploration, result in different connections to content, and enrich the greater learning community. Students can use the MmRs from the teacher and classmates to take action, express new understanding, communicate, and extend their own learning. One emerging area within the use of MMRs is the use of the arts in science education.

\subsubsection{Utilizing the Arts}

In recent years, the incorporation of the arts in science teaching has been introduced as a way to keep students' attention and engagement. This can be 
found particularly in discussions regarding the integration of science, technology, engineering, and mathematics (STEM). In this context, STEM with the addition of the arts is transformed to STEAM. The specific use of the arts has been theorized and described as an additional component of MMrs. Hwang and Taylor (2016) provided a STEAM framework with MMRS for SEN students. The arts should be incorporated into science instructional opportunities in a meaningful way that adds to student learning and helps connect across the other elements of sT EM (Hwang \& Taylor, 2016). Additional scholars have proposed that including the arts in science learning should be viewed as a spectrum of utilization (Taylor et al., 2018), with STEAM being the highest form of usage (Riley, 2016). Despite previous work from scholars, further research in utilizing a STEAM framework with MMRs in actual classrooms with SEN students is urgently needed.

Beyond its connection with MMRs, the arts can be utilized within the UDL framework. The three areas of UDL (engagement, representation, and action and expression) provide opportunities to utilize the arts for both teaching and learning. If considered fully, the use of the arts within the UDL structure allows SEN students to learn science and display what they have learned. In planning and instruction, teachers can utilize artistic products or performances as representations of science. During instruction, students can be allowed multiple artistic means to express their science background knowledge or learning progress. Finally, teachers can provide SEN students options that display what they have learned through artistic expression.

The application of MMRs to teaching/instructional opportunities contributes to student learning outcomes. SEN students, along with the rest of any given classroom community, are likely to demonstrate an improvement in achievement when MMRs are constructed. In addition, to student growth, teachers are also more likely to use MMRs as a reciprocal outcome of student success. Student and teacher engagement is strengthened in the science classroom when MmRs are utilized. Meaningful inclusion is obtainable and sustainable.

MMRs reflect one method for promoting the adaptive expertise of teachers and the malleable mindset of learners. Adaptive experts make the most of instructional opportunities to promote access to learning for SEN students. If a narrow range of instructional practices are utilized, a narrow range of learners will be reached; however, by utilizing a wide range of evidence-based practices, more diverse learners are able to access and enrich the learning community. MM Rs during instructional opportunities provide one way to diversify our approach to teaching and thus strengthen the diversity within the science community of learners. 


\subsection{Use of Communicative Systems in Science for SEN Students}

Assistive technology (AT) refers to tools that can support individuals with disabilities in various areas of life, including technologies designed to promote academic achievement (Parette \& Peterson-Karlan, 2007). For SEN students, this class of accommodations can reduce communicative and other barriers to meaningfully participating in science education. AT can thus be a critical component of a UDL approach to including such students in the science curriculum by engaging students with accessible materials and promoting means of expression in modalities most suited to their strengths. Digital texts, speech recognition technology, and augmentative and alternative communication are three examples of such technologies.

\subsubsection{Utilizing Digital Texts}

Digital texts, also referred to as e-texts or e-books, are books that are presented on computer or tablet screens that provide opportunities for students to engage with the text by touching images on the screens to produce animations, music, and/or sound and visual effects. Typically, these effects include reading the text out loud via a text-to-speech capability (sometimes in different languages) and providing definitions for selected vocabulary. This can be helpful for students with reading difficulties as well as students who have a difficult time comprehending abstract language. For example, Knight et al. (2015) investigated using BookBuilder by the Center for Applied Special Technology (2020) to create science e-texts with hyperlinks to vocabulary definitions, visual examples of science concepts, and embedded coaches who provided questions and modeled answers. These texts were then read aloud by a computer to four middle school students with AsD. The authors found that the participants mainly increased their number of correct vocabulary, comprehension, and application question responses after the science e-texts were introduced. Digital texts could thus be useful tools to reduce barriers for students with special needs in science by providing multiple means of representation: text to speech, vocabulary definitions for key terms, and pictorial representations of challenging concepts.

\subsubsection{Utilizing Speech Recognition Technology}

For SEN students who have difficulty with written expression, speech recognition technology (i.e., speech to text) could be helpful in writing in science notebooks and preparing laboratory and other kinds of scientific reports. Fitting into the UDL framework as a means of expression for SEN students to show what they have learned, speech recognition is now available on most software systems (e.g., Apple and Microsoft) and various web platforms (e.g., Google Docs). In an intervention designed by Miller, Krockover, and Doughty (2013), 
four secondary students with moderate to severe intellectual disabilities were able to use speech recognition software in creating electronic science notebooks for science inquiry investigations. Compared to the use of traditional science notebooks, the students demonstrated higher motivation, independence, and engagement in the investigations using electronic notebooks with speech recognition technology (and a digital stylus). They also acquired the same amount of science content in both notebook conditions. This study thus highlights one way that speech recognition technology can be used to support SEN students in both demonstrating their science learning and meaningfully engaging in inquiry investigations.

\subsubsection{Utilizing Augmentative and Alternative Communication}

Augmentative and alternative communication (AAC) includes all forms of communication (except oral speech) that can be used to express feelings, ideas, and needs (Beukelman \& Mirenda, 2013). All students with CCN - students who have no or limited natural speech and young students at risk for speech and language development - can benefit from AAC. This includes very young children, students with significant cognitive disabilities, and beginning communicators (Romski \& Sevchik, 2005). For students with some speech, use of AAC has been shown to correlate with modest gains in speech production (e.g., Romski et al., 2010). Thus, AAC is considered a critical intervention for individuals with no speech or whose speech is not sufficient for their full participation in school, home, and everyday life.

AAC is divided into unaided and aided systems. Unaided AAC refers to communication modes that do not rely on equipment and are done using your body alone. These systems include facial expressions, gestures, vocalizations, and sign languages (Beukelman \& Mirenda, 2013). Aided AAC systems include both low-tech and high-tech tools. Low-tech AAC systems involve non-electronic communication modes, such as communication boards consisting of pictures and/or symbols that an individual with CCN can point to. A number of different boards may be organized into a communication book that can be flipped through to access additional vocabulary. High-tech AAC systems include a variety of electronic applications and devices. A person using a high-tech system will touch a button or hotspot on a screen or device and the system will speak the word or phrase out loud. Examples of high-tech systems include speechgenerating devices (e.g., GoTalk4+) and tablet applications (e.g., GoTalkNow, SnapScene, and VoiceSymbol) available on iPads and other tablets. Typically, people with CCN will rely on both unaided and aided systems to communicate with others. For example, a student may use sign and vocalizations with teachers familiar with sign and use an AAC application on an iPad with classmates 
and other people who do not know sign. The same student may also use low-tech communication boards during activities that could risk damage to a high-tech electronic system (e.g., outside play, science experiments, and water activities).

For students who are not able to directly select an item by pointing to it or pressing a button or a screen, there are alternative means to access AAC systems. People with mobility impairments can use switches and joysticks to activate AAC systems and select vocabulary (Beukelman \& Mirenda, 2013). Eye-gaze technology, in which a camera or a communication partner tracks an individual's eye movements, has been shown to be effective for people who cannot make consistent motor movements required for switch access. It is important to note someone using AAC should be independent in doing so. Their communication partner should not guide or hold their hand, arm, or other body part, as that can lead to selection not being under the control of the AAC user (i.e., the partner can be subconsciously choosing what to say). Instead, every effort should be made to find a way for a student with CCN to communicate independently using switches, eye-gaze technology, or other methods of alternative access.

AAC can thus be thought of as providing students with multiple means of engagement and expression and action in the UDL framework. AAC makes it possible for students with CCN to be more autonomous during academic activities, which promotes engagement and learning. These systems also promote the use of varying methods and use of media for SEN students to show what they are learning.

Given this information, what do we know about the use of AAC systems to promote academic engagement and expression, especially in science classes? Boruta and Bidstrup (2012) suggest modeling language structures and vocabulary related to grade-level concepts in students' AAC systems to make math and science curricula more accessible. They also suggest using manipulatives and activating prior knowledge in science lessons. As an example, when teaching about earthquakes, the teacher should ask the student what they know about earthquakes, provide a tactile example of earthquake topography, and model earthquake vocabulary that has been programmed into the AAC system.

$\mathrm{Wu}$, Chen, Lo, and Chiang (2020) recently investigated using peer-mediated interventions with AAC to improve science learning of students with significant cognitive disabilities in Taiwan. They added key terms and definitions for buoyancy and electricity concepts (e.g., buoyancy, conductive, and nonconductive) to participants' AAC systems and adapted instructional activities using tangible materials (e.g., clay boats, paper clips, and broken electronic circuits) for participants and peers to complete. Their typically developing peers 
were provided tutoring scripts that directed them to model the key terms on the participants' AAC systems, model and encourage interaction with the science materials, ask questions of participants with disabilities, and complete the assignment sheet together. SEN student participants were assessed on science knowledge by answering multiple choice comprehension and application questions by pointing to one of three pictorial response options. Results indicated that the SEN students participants improved both their science knowledge and communication responses as a result of this intervention. A key finding is that use of both MMRs and AAC led to increased science knowledge, suggesting that MM Rs benefits students who use AAC in science instruction.

Equally important is the use of aided language stimulation and communication partner training in creating successful interventions using AAC. Aided language stimulation is the practice of modeling the use of the AAC system (e.g., by pointing or selecting items) while also providing verbal input to the person with CCN. Use of aided language stimulation has been found to be highly effective in supporting comprehension and expression for individuals with CCN (O'Neill et al., 2018). When training educators, families, peers, or other communication partners of SEN students to operate and program AAC systems, training in providing aided language stimulation should also be given. For example, communication partners can be taught to model the use of the AAC system, wait for a response from SEN students, and then reply to any communicative response by both speaking and using the AAC system (Sennott \& Mason, 2015).

Assistive technology can thus be used to support the science learning of SEN students who have difficulties with receptive and expressive language, reading comprehension, and written expression. Providing students with access to digital texts, speech recognition technology, and AAC promotes student engagement with science knowledge and inquiry learning. Digital texts allow multiple means of representation, supporting the learning of science concepts and vocabulary. AAC systems and speech recognition technology provide alternative means of expression for SEN students who may be limited in using oral and written expression. The movement towards science for all and meaningful inclusion will greatly benefit from the use of AT to support learning for SEN students.

While the pedagogical approaches of MMRs and use of AT/AAC are common in special education, application in science classrooms may be considered novel given the depth of training, implementation experience, and successful outcomes with these approaches by science teachers. From veteran teachers to recently graduated science teachers, very few have completed coursework on AT and AAC. Training in this is foundational, so a lack of training creates a 


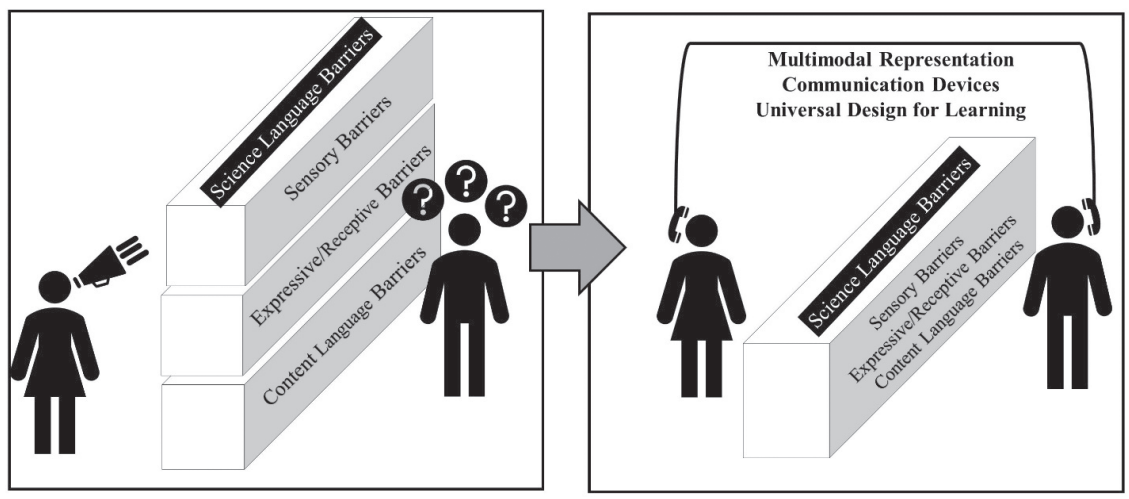

FIGURE 1 Conceptual framework for reducing science language barriers

disconnect in how this approach can be used universally to support the inclusion of all learners.

The application of MMRs and AT/AAC may even have novelty for science teachers with awareness and training. For many reasons, science teachers may have knowledge of these pedagogies and still lack experience with implementation. Furthermore, fidelity can be an issue. When these practices are applied without fidelity, they may be less effective. Teachers do not repeat practices that fail to get desired results. Hence, the practices of MMR and AT/AAC within a UDL framework in the science classroom can be considered novel in terms of their actual application for the purpose of breaking down language barriers. See Figure 1 for the conceptualization of reducing science language barriers.

Whether the inclusion of SEN students in the science classroom is new or ongoing, current science educators are able to capitalize on the evidence base that is present and continues to grow with the momentum of including SEN students in science. The research base for teaching science to SEN students strives to reach comparability to research in the content areas of math and reading. Much work has been done to address the major barriers created by the disconnects between language, literacy, and science. It is not uncommon to recognize that language can impede progress in science, as this issue is not necessarily specific to SEN students. However, the view of science literacy as a barrier to progress is slightly more novel. Certainly, the effects of science literacy are ever present as we progress through the COVID-19 pandemic. The exclusion or lack of meaningful inclusion of SEN students in opportunities 
to construct science literacy is problematic at all levels. Fortunately, there are supports that include MMRs and AAC. These strategies and technologies can be used to support all learners but are necessary for the success of SEN students in science education. To summarize, science educators can equip themselves with practices that can be universally applied to create a diverse and inclusive science-learning community.

MMRs and AT strategies, especially AAC, incorporate the principles of UDL by allowing SEN students to engage with learning in multiple ways, gain access to various representations of science concepts, and express what they have learned using modalities that circumvent language barriers. If these strategies are implemented by educators, both motivation for science learning and development of science knowledge and inquiry skills will increase. This begins with two fundamental understandings. First, all students can learn and contribute to the learning of others, regardless of exceptionality. Second, teaching science requires the use of multiple methods. A singular instructional design addresses a singular body of learners. The success of SEN students in science hinges on effective instruction.

The strategies of MMRs and use of AAC technologies support science educators' efforts to bridge the connections between language, literacy, and science. These approaches to science instruction promote science achievement for SEN students and support the goals set forth by the science for all movement. More important than knowing these strategies is understanding the relevance of their application. Science educators are in a unique and unequivocal position to advance the field of science and improve science literacy, both locally and globally. The golden measure of educator effectiveness is student achievement. The bottom line is that if SEN students are not given an equitable opportunity to learn science, they cannot reach competitive levels of achievement. Science educators cannot claim to be effective until this cornerstone is in place.

\section{Abbreviations}

AAC alternative and augmentative communication

ADHD attention deficit/hyperactivity

ASD autism spectrum disorder

AT assistive technology

CCN complex communication needs

CWPT class-wide peer tutoring

EBD emotional and behavioral disorders

ELL English language learners 


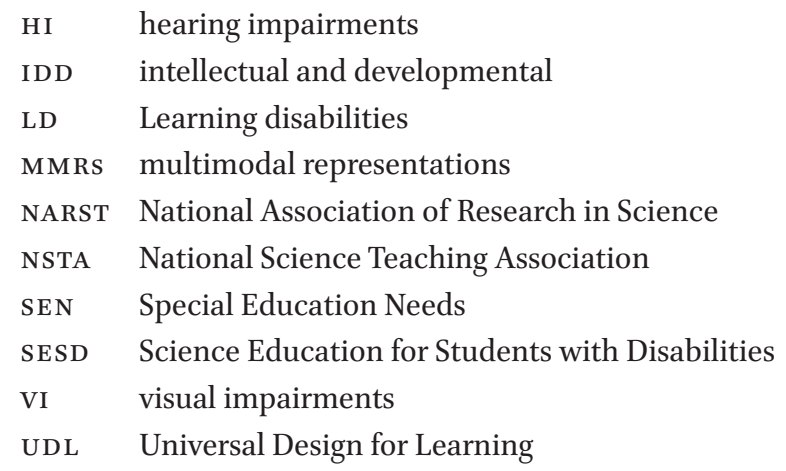

\section{Ethical Considerations}

The data reported in this study does not require human subjects' approval.

\section{About the Authors}

Susannah Boyle Ph.D. is an Assistant Professor of special education at Millersville University, where she teaches courses on inclusion, severe disabilities, and classroom management. Her research interests include assistive technology (with a focus on augmentative and alternative communication), supporting students with severe disabilities, and special education teacher preparation. She has presented AAC workshops for a variety of audiences, including pre-service and in-service teachers, early intervention providers, and families.

Karen L. Rizzo Ph.D. is an Assistant Professor of special education at Saint Martin's University. Her research interests are in teacher preparation and STEM education. Karen's teaching interests include inclusive special education foundations, evidence-based instruction for teaching math and science to students with disabilities, and assistive technology. Prior to working in higher education, Karen worked in a variety of educational settings, primarily K-6 as a special education teacher.

Jonte' C. Taylor (JT) Ph.D. is an Assistant Professor of Special Education at Penn State University. His research includes examining effective strategies for inclusive STEM education for students with disabilities classroom/behavior management strategies for students and teachers, and improving school/ 
classroom-based relationships. Prior to working in higher education, he taught in a variety of settings including juvenile justice and self-contained classroom settings and with a variety of students including adults with severe cognitive disabilities, children with Autism Spectrum Disorder, and students with Emotional/Behavioral Disorders. He is currently on the executive committee for Council for Children with Behavior Disorders, a member of the National Science Teachers Association's Special Needs Advisory Board, and the president of Science Education for Students with Disabilities.

\section{References}

American Association for the Advancement of Science. (1990). Project 206r: Science for all Americans. Oxford University Press.

American Psychiatric Association. (2013). Diagnostic and statistical manual of mental disorders (5th ed.). American Psychiatric Association.

Beukelman, D. R., \& Mirenda, P. (2013). Augmentative \& alternative communication: Supporting children and adults with complex communication needs. Paul H. Brookes Publishing.

Boruta, M. C., \& Bidstrup, K. (2012). Making it a reality: Using standards-based general education science and math curriculum to teach vocabulary and language structures to students who use AAC. Perspectives on Augmentative and Alternative Communication, 21 (3), 99-104.

Bowman-Perrott, L., Greenwood, C. R., \& Tapia, Y. (2007). The efficacy of CWPT used in secondary alternative school classrooms with small teacher/pupil ratios and students with emotional and behavioral disorders. Education and Treatment of Children, 30, 65-87. https://www.doi.org/10.1353/etc.2007.0014.

Center for Applied Special Technology [CAST]. (2011). Universal design for learning guidelines.

Center for Applied Special Technology. (2020). CAST UDL book builder. http://book builder.cast.org/.

Darling-Hammond, L. (1998). Teachers and teaching: Testing policy hypotheses from a national commission report. Educational Researcher, 27 (1), 5-15.

Dexter, D. D., Park, Y. J., \& Hughes, C. A. (2011). A meta-analytic review of graphic organizers and science instruction for adolescents with learning disabilities: Implications for the intermediate and secondary science classroom. Learning Disabilities Research \& Practice, 26 (4), 204-213.

Eisenmajer, N., Ross, N., \& Pratt, C. (2005). Specificity and characteristics of learning disabilities. Journal of Child Psychology and Psychiatry, 46 (10), 1108-1115. 
Farrand, K., Wild, T., \& Hilson, M. P. (2016). Self-efficacy of students with visual impairments before and after participation in an inquiry-based camp. Journal of Science Education for Students with Disabilities, 19 (1), 5 .

Fensham, P. J. (1985). Science for all: A reflective essay. Journal of curriculum Studies, 17 (4), 415-435.

Fensham, P. (2008). Science education policy-making: Eleven emerging issues. UNEsco.

Gajria, M., Jitendra, A. K., Sood, S., \& Sacks, G. (2007). Improving comprehension of expository text in students with LD: A research synthesis. Journal of Learning Disabilities, 40, 210-225. https://doi.org/10.1177/00222194070400030301.

Gardner, P. L. (1974). Language difficulties of science students. Australian Science Teachers Journal, 20 (1), 63-76.

Heinrich, S., Knight, V., Collins, B. C., \& Spriggs, A. D. (2016). Embedded simultaneous prompting procedure to teach STEM content to high school students with moderate disabilities in an inclusive setting. Education and Training in Autism and Developmental Disabilities, 51 (1), 41-54.

Hwang, J., \& Taylor, J. C. (2016). Stemming on STEM: A STEM education framework for students with disabilities. Journal of Science Education for Students with Disabilities, $19(1), 39-49$.

Israel, M., Shehab, S., \& Quentin, M. W. (2018). Increasing science learning and engagement for academically diverse students through scaffolded scientific inquiry and universal design for learning. In M. Koomen, S. Kahn, C. L. Atchison, \& T. A. Wild (Eds.). Towards inclusion of all learners through science teacher education. Brill | Sense. https://doi.org/10.1163/9789004368422_o22.

Jegede, O., \& Kyle, J. W. (2007). Concerns and issues in scientific literacy in the postmodern era. Paper presented at the Annual Meeting of the National Association for Research in Science Teaching, New Orleans, LA.

Kahn, S., \& Lewis, A. R. (2014). Survey on teaching science to K-12 students with disabilities: Teacher preparedness and attitudes. Journal of Science Teacher Education, 25 (8), 885-910.

Kaldenberg, E. R., Watt, S. J., \& Therrien, W. J. (2015). Reading instruction in science for students with learning disabilities: A meta-analysis. Learning Disability Quarterly, $38(3), 160-173$.

Kemp, A. C. (2000). Science educator's views on the goal of scientific literacy for all: An interpretive review of the literature. Paper presented at the Annual Meeting of the National Association for Research in Science Teaching, New Orleans, LA.

Knight, V. F., Smith, B. R., Spooner, F., \& Browder, D. (2012). Using explicit instruction to teach science descriptors to students with autism spectrum disorder. Journal of Autism and Developmental Disorders, 42 (3), 378-389. https://doi.org/10.1007/ s10803-011-1258-1. 
Knight, V. F., Wood, C. L., Spooner, F., Browder, D. M., \& O’Brien, C. P. (2015). An exploratory study using science eTexts with students with autism spectrum disorder. Focus on Autism and Other Developmental Disabilities, 30 (2), 86-99.

Kurz, K. B., Schick, B., \& Hauser, P. C. (2015). Deaf children's science content learning in direct instruction versus interpreted instruction. Journal of Science Education for students with disabilities, 18 (1), 23-37.

Lartec, J. K., \& Espique, F. P. (2012). Communication strategies of teachers educating students who are legally blind in the general education setting. Insight: Research \& Practice in Visual Impairment \& Blindness, 5 (2), 70-82.

Lieu, J. E., Tye-Murray, N., Karzon, R. K., \& Piccirillo, J. F. (2010). Unilateral hearing loss is associated with worse speech-language scores in children. Pediatrics, 125 (6), e1348-e1355.

Lord, C. \& Bishop, S. (2010). Autism spectrum disorders: Diagnosis, prevalence, and services for children and families, Social Policy Report V24, 2, 1-27.

Mastropieri, M. A., Scruggs, T. E., Norland, J. J., Berkeley, S., McDuffie, K., Tornquist, E. H., \& Connors, N. (2006). Differentiated curriculum enhancement in inclusive middle school science: Effects on classroom and high-stakes tests. The Journal of Special Education, 40 (3), 130-137.

McLeod, S., \& McKinnon, D. H. (2007). The prevalence of communication disorders compared with other learning needs in 14,500 primary and secondary school students. International Journal of Language and Communication Disorders, 42 (S1), 37-59.

Miller, B. T., Krockover, G. H., \& Doughty, T. (2013). Using iPads to teach inquiry science to students with a moderate to severe intellectual disability: A pilot study.Journal of Research in Science Teaching, 50 (8), 887-911.

Miller, R. (2004). Public understanding of, and attitudes toward, scientific research: What we know and what we need to know. Public Understanding of Science, 13 (3), 273-294.

National Institute on Deafness and Other Communication Disorders. (2016, May 19). Quick statistics about voice, speech, language. https://www.nidcd.nih.gov/health/ statistics/quick-statistics-voice-speech-language.

O’Neill, T., Light, J., \& Pope, L. (2018). Effects of interventions that include aided augmentative and alternative communication input on the communication of individuals with complex communication needs: A meta-analysis. Journal of Speech, Language, and Hearing Research, 61 (7), 1743-1765.

Parette, H. P., \& Peterson-Karlan, G. R. (2007). Facilitating student achievement with assistive technology. Education and Training in Developmental Disabilities, 42 (4), 387-397.

Riley, S. (2016, November 20). Is it arts integration or STEAM? [Web log post]. Retrieved from https://educationcloset.com/2016/11/30/arts-integration-steam/. 
Rizzo, K. L., \& Taylor, J. C. (2016). Effects of inquiry-based instruction on science achievement for students with disabilities: An analysis of the literature. Journal of Science Education for Students with Disabilities, 19 (1), 2.

Romski, M., \& Sevcik, R. A. (2005). Augmentative communication and early intervention: Myths and realities. Infants \& Young Children, 18 (3), 174-185.

Romski, M., Sevcik, R. A., Adamson, L. B., Cheslock, M., Smith, A., Barker, R. M., \& Bakeman, R. (2010). Randomized comparison of augmented and nonaugmented language interventions for toddlers with developmental delays and their parents. Journal of Speech, Language, and Hearing Research, 53 (2), 350-364.

Scruggs, T. E., Mastropieri, M. A., Bakken, J. P., \& Brigham, F. J. (1993). Reading versus doing: The relative effects of textbook-based and inquiry-oriented approaches to science learning in special education classrooms. The Journal of Special Education, 27 (1), 1-15.

Seifert, K., \& Espin, C. (2012). Improving reading of science text for secondary students with learning disabilities: Effects of text reading, vocabulary learning, and combined approaches to instruction. Learning Disability Quarterly, 35 (4), 236-247. https://doi.org/10.1177/0731948712444275.

Sennott, S. C., \& Mason, L. H. (2016). AAC modeling with the iPad during shared storybook reading pilot study. Communication Disorders Quarterly, 37 (4), 242-254.

Sharma, U., Forlin, C., \& Loreman, T. (2008). Impact of training on pre-service teachers' communication Strategies attitudes and concerns about inclusive education and sentiments about persons with disabilities. Disability and Society, 23 (7), 773-785.

Taylor, J. C., Hwang, J., Rizzo, K. L., \& Hill, D. (2020). Supporting science-related instruction for students with intellectual and developmental disabilities: A review and analysis of research studies. The Science Educator, 27 (2), 1-12.

Taylor, J. C., Riden, B., \& Markelz, A. (2018). The arts, project-based learning, and students with challenging behaviors: The alignment of strengths, usage, and outcomes. VSA Kennedy Center Intersections: Exemplary Programs and Approaches Professional Papers Series, 4, 55-69.

Taylor, J. C., Rizzo, K. L., Hwang, J., \& Hill, D. (2020). A review of research on science instruction for students with autism spectrum disorder. School Science and Mathematics, 120 (2), 116-125.

Therrien, W. J., Taylor, J. C., Hosp, J. L., Kaldenberg, E. R., \& Gorsh, J. (2011). Science instruction for students with learning disabilities: A meta-analysis. Learning Disabilities Research \& Practice, 26 (4), 188-203.

Therrien, W. J., Taylor, J. C., Watt, S., \& Kaldenberg, E. R. (2014). Science instruction for students with emotional and behavioral disorders. Remedial and Special Education, $35(1), 15^{-27}$.

United Nations Educational, Scientific and Cultural Organization (1994). The salamanca statement and framework for action on special needs education. UNESCO. 
Villanueva, M. G., \& Hand, B. (2011). Science for all: Engaging students with special needs in and about science. Learning Disabilities Research \& Practice, 26 (4), 233-240.

Villanueva, M. G., Taylor, J., Therrien, W., \& Hand, B. (2012). Science education for students with special needs. Studies in Science Education, 48 (2), 187-215.

Wu, Y. P., Chen, M. C., Lo, Y. Y., \& Chiang, C. H. (2020). Effects of peer-mediated instruction with AAC on science learning and communitive responses of students with significant cognitive disabilities in Taiwan. Research and Practice for Persons with Severe Disabilities. https://doi.org/10.1177/1540796919900955. 